\title{
From healthy to vulnerable: older men’s experiences with prostate cancer and cancer care
}

Birgit van Ee, MSc'1, Prof Mariët Hagedoorn, $\mathrm{PhD}^{2}$, Aafke Honkoop, MD/PhD³, Ad Kamper, $\mathrm{MD} / \mathrm{PhD}^{3}$, Prof Joris Slaets, $\mathrm{PhD}^{2 / 4}$, Prof Carolien Smits, $\mathrm{PhD}^{1}$

${ }^{1}$ Windesheim University of Applied Sciences, Research Groep Innovating with Older Adults, Zwolle, The Netherlands, 'University of Groningen, University Medical Center Groningen, Groningen, The Netherlands, ${ }^{3}$ ssala Hospital, Zwolle, The Netherlands, ${ }^{4}$ Leyden Academy on Vitality and Ageing, Leiden, The Netherlands

\section{Background and research aim}

- Prostate cancer is most frequently diagnosed in older men

- Information on their experiences is lacking

- Insight into the experiences, needs and wishes of older men with prostate cancer may enhance personalised care

\section{"I need to have a bathroom}

nearby, no long travels, and I am

easily fatigued"

\section{Methods}

- Semi-structured interviews with 22 men (70+) with prostate cancer

- Topics: experiences with cancer, support, information and decision making, and care needs

- Content analysis and affinity diagramming

\section{Results}

- The experiences of men with prostate cancer varied from almost no complaints to many health-related problems caused by prostate cancer, treatment, comorbid diseases and ageing

- Urinary and bowel problems limited daily life, and wearing a catheter as well as sexual dysfunctioning was very disturbing to some men

- Men felt restrained to discuss their problems with their children and acquaintances

- Some men missed the care from nurse practitioners and adequate information from their specialists

- The men enjoyed the spontaneous social interactions with fellow-patients and professionals during radiotherapy appointments

\section{"The only one I told was my} partner because of the stigma.

My children have their own worries and then they would also worry about dad"

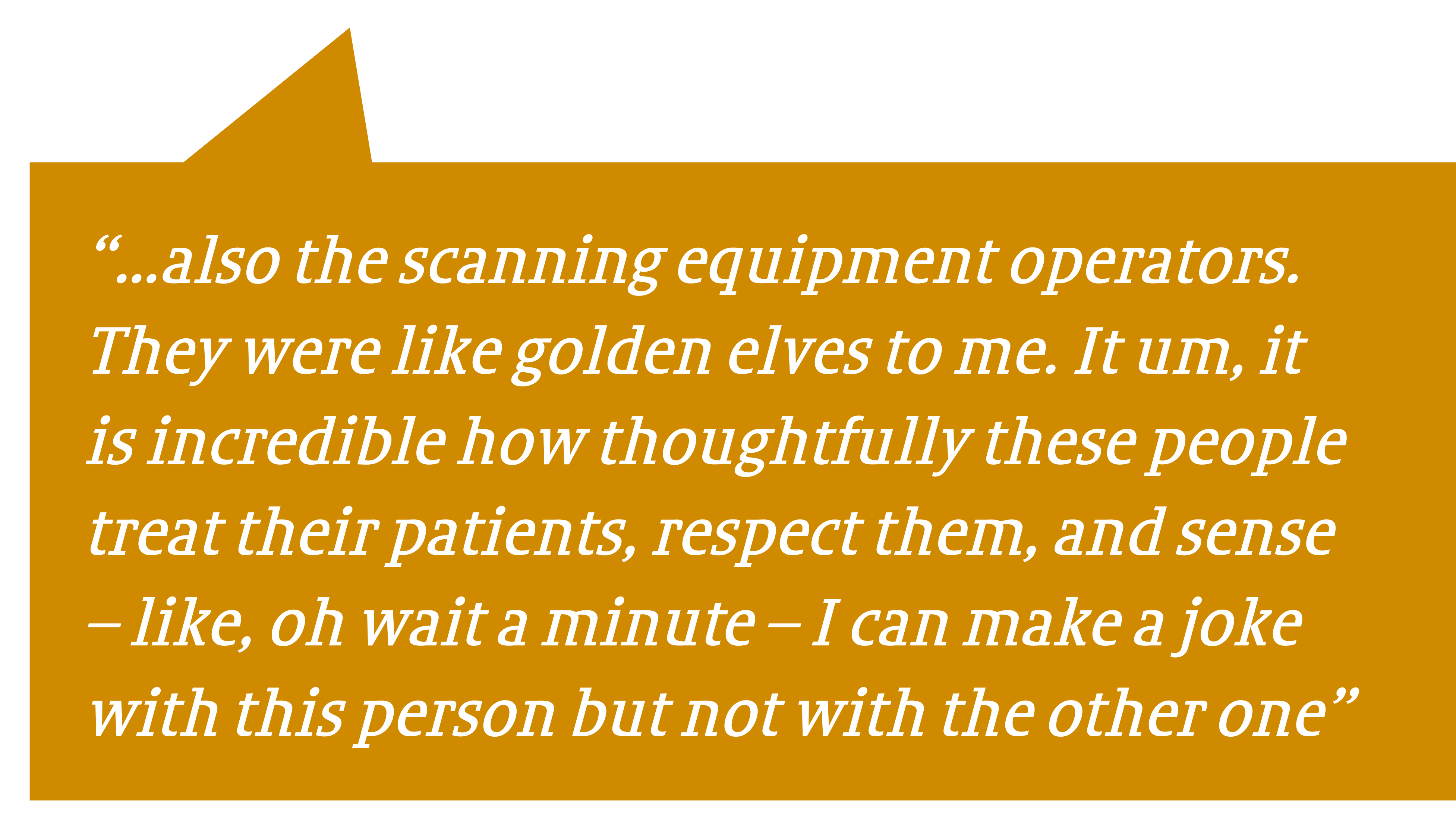

\section{Conclusions}

- Lack of social support and health complications may indicate additional care needs

- Sexual functioning needs more attention

- Hospitals may offer more informal opportunities for older men to share their experiences with other men with prostate cancer

- Nursing care to men with prostate cancer may be worth increasing

Contact: ib.van.ee@windesheim.nl 